\title{
Avaliação sócio-ambiental para implantação de sistema de tratamento de esgoto na região da Vila Cachoeirinha, comunidade e entorno, Campos do Jordão,SP.
}

\author{
Adriana Prestes \\ Carlos Benedicto Marcondes Cabral \\ Alessandro Palma \\ Instituto Àguas do Prata-IAP \\ Rua Próspero Olivetti, 598 \\ Sala 3, Abernéssia, Campos do Jordão, SP \\ adriana.prestes@iapbrasil.org \\ Tecnogaia do Brasil LTDA \\ Empresa de Consultoria e Projetos de Engenharia \\ Rua Sete de setembro, 473 - sala 1- Centro - Tremembé \\ CEP: $12120-000$ \\ São Paulo \\ palma@tecnogaia.com.br
}

\section{Projeto executado com recursos FEHIDRO/SINFEHIDRO SM-72}

\begin{abstract}
There is no treatment for domestic effluents in Campos do Jordao, and the number of houses connected to the sure system is very low even though the region is considered an area of special interest for preservation, and it's use is restricted by several laws. High rates of raw dejects are released in the studied area at a single point into the Itatinga lake $(640.000 \mathrm{~L} /$ day) creating a biochemical demand for oxygen of $173 \mathrm{mg} / \mathrm{L}$, therefore exposing the inhabitants to a hazardous situation and clearly compromising the water resources of the region. The Itatinga lake is an important contributor to the Capivari river, the main water course in the region. The present study is a contribution to discuss possible solutions for the domestic effluent problem in degraded urban areas with a consolidated level of occupation.
\end{abstract}

Palavras chave: saneamento básico, avaliação sócio-ambiental, poluição de águas superficiais

\section{Introdução}

Além de integrar a UGRHI-1 como área produtora de recursos hídricos, Campos do Jordão, é caracterizada como Área de Proteção Ambiental (APA) através dos seguintes dispositivos legais; Lei Municipal no. 1484/85 de 09/04/85, regulamentada pelo Decreto no. 1850/88 de 31/05/88; Decreto Estadual 20956/83 reiterado pela Lei Estadual no. 4105 de 26 de junho de 1984; Decreto Federal 91304 de 3 de junho de 1985. Apesar dos dispositivos legais que protegem o meio ambiente do município de Campos do Jordão, a cidade não possui tratamento de esgoto. Com o crescente aumento da população, atualmente estimada em 55 mil habitantes,segundo dados do IBGE, a situação é de acelerada degradação ambiental, que se torna, ainda mais grave nos bairros populares com maior adensamento populacional.

\subsection{Breve Histórico sobre a área de estudo}

Após mais de duas décadas de embates jurídicos, os moradores da Vila Cachoeirinha, que residem em faixa superior a 30 metros da margem do Córrego Brejo Grande, conquistaram a Permissão de Uso de Direito de continuar em suas casas, atendendo ao dispositivo da Constituição Federal que prevê que o imóvel tem que cumprir sua função social. Eles foram recebidos pelo Prefeito de Campos do Jordão, Dr João Paulo Ismael, que entregou o documento de permissão pessoalmente ao grupo de 21 moradores 
beneficiados no mês de maio de 2008. A permissão veio depois de um período tenso entre os moradores e o poder público, quando através de uma ação judicial, havia sido solicitada a retirada dos moradores da área. Durante o mês de dezembro de 2007, na época da comemoração das festas natalinas, havia sido solicitado pelas autoridades o corte de água e de luz, determinando revoltas e protestos na população, que realizou manifestações públicas no local com a queima de pneus e outros materiais. A permissão foi concedida pela Empresa Municipal de Habitação - Emuab - em que é especificada a proibição de edificação na faixa dos 30 metros da margem do rio, após realização de levantamento topográfico em que foi constatado que o grupo não residia em área de terra em que é vetada construção de moradias por lei federal, pelos órgãos ambientais, inclusive do Conselho Nacional do Meio Ambiente (Conama). Atualmente aguarda-se a manifestação do Poder Público, sobre a regularização fundiária dos lotes.

\section{Objetivo}

Realizar um estudo preliminar da área denominada Vila Cachoeirinha,em Campos do Jordão, com a finalidade de fornecer dados sobre a carga poluidora que permitam o futuro redimensionamento da rede de coleta e/ou a construção e instalação de uma estação de tratamento de esgoto na área.

\section{Metodologia}

Foi utilizada a metodologia de "Diagnóstico Ambiental"(SMA, 2005) que forneceu as bases técnicas para a divisão da área de estudo em zonas de acordo com as necessidades de proteção, conservação e recuperação dos recursos naturais e o desenvolvimento sustentável. Nesse sentido, se fez necessário à realização de estudos de meio, consultas a documentação e mapeamentos dos fatores antrópicos, bióticos, abióticos existentes na área de estudo e sua relação com o contexto social. O diagnóstico contemplou, três etapas:1)Levantamento de dados e informações, que foi contemplado pela aplicação de questionário sócio-econômico, levantamento planialtimétrico e análise da situação atual de uso e ocupação do solo. Com relação ao questionário, as perguntas foram estruturadas em parceria com a comunidade e aplicado pela escola pública do bairro.2)Indicação de áreas homogêneas, que permitiu obter o conhecimento detalhado da área em estudo o que se constituí um pré-requisito fundamental para a fase de identificação das áreas prioritárias para proteção e recuperação ambiental.3)Discussão dos resultados obtidos e indicação de prognósticos para a área de estudo.

\section{Resultados e Discussão}

\subsection{Obtenção dos dados sócio-econômicos.}

O questionário foi aplicado através de parceria realizada com a Escola Pública localizada na área de estudo. Através da atuação das professoras, os questionários foram distribuídos a todos os alunos da escola. Além desses também foram aplicados, por técnicos do IAP, questionários para a comunidade, não relacionada com a escola, dentro da área de estudo . Foram distribuídos cerca de 1500 questionários. Foram respondidos corretamente cerca de 550 questionários.

\subsection{Análise dos dados sócio econômicos}

A média de pessoas por habitação é em torno de 5 a 7 pessoas ( $45 \%$ da população pesquisada). Esse dado indica um alto grau de adensamento populacional dentro da área de pesquisa, fenômeno também observado em outros bairros populosos da cidade. A faixa salarial mais freqüente foi a de até 4 salários ( $83 \%$ da população pesquisada).O elemento que mais "pesa" no orçamento das famílias da área de estudo é a alimentação,indicando que 
possivelmente algumas essas famílias encontram-se em situação de risco, quanto à questão da segura alimentar. Além de numerosas, as famílias são formadas por uma alta porcentagem de crianças, já que 33\% das famílias pesquisadas possuíam entre 3 e 4 fillhos em idade escolar. É interessante notar que apesar do baixo grau de escolaridade os pais não retomam os estudos, mesmo havendo oferta gratuita do nível supletivo na área. Quando perguntados se algum adulto freqüenta a escola, apenas 10\% afirmaram que sim. Diante do exposto, é razoável assumir que boa parte do o grupo de moradores entrevistados não possuía seus imóveis dentro de uma situação fundiária regular, apesar disso $70 \%$ das pessoas entrevistadas afirmaram possuir casa própria. Ainda, no item que indicava "outros", somente alguns (12\%) informaram que residiam em "áreas verdes", portanto invadidas. Assim concluí-se que apesar de eventuais irregularidades na situação fundiária, os moradores percebem suas casas como próprias. Constamos a universalização do uso da televisão, porém em comparação, os moradores da área pesquisada tem pouco acesso a informação, considerando que apenas $10 \%$ dos domicílios pesquisados possuem acesso a internet, ou ainda apenas $21 \%$ possuem computadores. Os dados obtidos junto ao questionário sócio econômico confirmam a avaliação de que o bairro possui um padrão popular de habitações, pois mesmo as famílias sendo numerosas, a maioria das habitações pesquisadas, possuem apenas um banheiro e dois quartos, sendo $42 \%$ das casas sem quintal, isto é sem área útil externa. Um ponto importante a ser considerado é a relação entre higiene e saneamento básico, isto é, como conduzir essas famílias a uma melhor condição de saúde se não há saneamento básico na área e as condições físicas das habitações não permitem boas condições de higiene. A maioria da população na área pesquisada utiliza água distribuída pela Sabesp, porém apenas $1 \%$ declarou utilizar água de mina. Todavia notamos que esse dado não condiz com a realidade já que na área de estudo é uma situação comum encontrar residências que utilizam tanto a água de nascentes quanto da Sabesp, inclusive podendo acontecer mistura das águas nas caixas de água. Alguns entrevistados indicaram a conta de água como o item que mais pesava no orçamento, assim como a água de mina é gratuita alguns moradores entendem que o risco de consumir água não tratada é compensatório. Apesar da área possuir coleta de lixo regular, e inclusive seletiva, de acordo com os moradores, esse processo não é muito eficiente visto que, ainda existem moradores que enterram ou queimam o lixo. Também de acordo com nossa experiência sobre a área de estudo, é comum a presença de lixo espalhado pelas vias públicas, tanto pela coleta acontecer apenas 3 vezes por semana, como também pelo fato que a região possui muitas habitações precárias, isto é, casa localizadas em locais de difícil acesso, cujos moradores necessitam depositar o lixo em caçambas ou lixeiras comunitárias. Esse quadro é ainda mais grave, quando consideramos que os moradores possuem grande número de animais domésticos, como cães e gatos que transitam livremente pela área, atacando o lixo e contribuindo para o aspecto degradado. Esse fato também é comprovado quando consideramos que $76 \%$ dos entrevistados, tem utilizado restos de alimentos para manter os animais de estimação. Ainda, um outro dado relevante é o de que apenas $15 \%$ dos entrevistados, levam regularmente seus animais ao veterinário, ou ainda que só $40 \%$ vermífuga os animais regularmente, caracterizando um grave quadro de saúde pública.

\subsection{O Problema do lançamento de esgoto doméstico}

É possível inferir pela avaliação dos resultados obtidos quanto à questão do destino do lançamento, que apesar das condições degradas da área, a população encontra-se alheia ao fato de que em Campos do Jordão não existe o tratamento de esgotos, apenas coleta, assim $40 \%$ dos entrevistados assinalou a alternativa de que os esgotos domésticos são tratados pela Sabesp, quando em realidade não existe tratamento de esgoto. Uma parcela de 
$35 \%$ dos entrevistados assinalou que os esgotos vão para o rio, sem tratamento. Um dado digno de nota, foi que a freqüência dos entrevistados que afirmou não saber o destino do esgoto, é quase a mesma dos que assinalaram que o esgoto vai para fossa $(13 \%$ e $12 \%$ respectivamente). É interessante notar que a área apresenta uma condição de solo desfavorável a infiltração, portanto e de acordo com os dados obtidos, as fossas existentes possivelmente encontram-se liberando esgoto diretamente na área pesquisada. Em resumo, a população pesquisada, apesar da evidente degradação ambiental, ignora o destino do seu esgoto. Esse fato fica claro, quando consideramos que apesar de 98\% serem favoráveis a uma estação de tratamento de esgotos, quando perguntados sobre o tipo de fossa, $68 \%$ dos entrevistados não responderam; $16 \%$ responderam que possuem sistema de fossa "a céu aberto", isto é uma vala; inclusive tendo $8 \%$ dos entrevistados, respondido que, seus dejetos são lançados diretamente no rio. É importante considerar que de acordo com a condição fundiária da área, muitos domicílios existindo em "área verde", portanto invadida, os mesmos não estejam conectados a rede de esgoto, determinando que o lançamento de seus dejetos seja realizado diretamente nos cursos de água ou no solo. Isto significa que o cadastro de lançamentos conhecido, pode ser muitas vezes inferior ao lançamento efetivo. Ainda há que se considerar que mesmo as residências que possuem ligações com o sistema de água e esgoto, muitas vezes se utilizam tanto de fontes alternativas de abastecimento não cadastradas, tais como minas d'água. Os moradores lançam seus esgotos, apesar da existência da rede, em galerias pluviais, simplesmente por acreditar que é mais vantajoso, visto que muitas vezes a rede de esgoto está mais distante da residência do que a rede pluvial. Em dias de chuvas fortes, comuns na região durante o verão, vemos que as tampas dos bueiros marcados como esgotos, "saltam", infelizmente não só nessa área em particular, mas em toda a cidade. Isto indica que as galerias de chuvas estão conectadas clandestinamente à rede de esgoto. A seguir transcrevemos um relato de um jovem morador da área, que ilustra a percepção que os moradores tem da área: "Na minha casa não tem tratamento de esgoto e a gente joga o esgoto na Cachoeirinha do Jardim Monte Carlo. Uma vez, estourou um cano de esgoto, o dono da casa onde passava o esgoto foi reclamar para o fiscal e todo mundo se reuniu para ajudar a arrumar. Lá em casa só chega água e luz, mas tratamento de esgoto que é bom, nada, ainda bem que lembraram da coleta de lixo."

\subsection{Qualidade das águas superficiais}

A região da Vila Cachoeirinha, apesar de estar localizada à cerca de $3 \mathrm{~km}$ do bairro central da cidade Vila Abernéssia (região de agências bancárias e comércio movimentado), é uma região carente com moradores vivendo abaixo da linha da pobreza, essa área apesar de ser uma Área de Preservação Permanente (APP) apresenta um baixo índice de salubridade ambiental. Dentro do bairro, formado por cerca de 8.000 pessoas, divididas em aproximadamente 1.000 famílias, existem moradores que vivem em um "fundo de vale" onde os dejetos e o lixo são depositados no solo e no córrego que corta a área, de forma clandestina e a céu aberto, criando uma situação insustentável do ponto de vista ambiental. A drenagem da área termina em uma represa denominada Itatinga que desde 2007 passa por um projeto de revitalização, financiado pelo FEHIDRO e sob responsabilidade da Prefeitura Municipal de Campos do Jordão. Uma das áreas mais críticas localiza-se a jusante da represa e é o ponto de lançamento de esgoto "in natura" no córrego Brejo Grande, entre a rua Escócia e o ponto de ônibus da praça Vivaldo Antunes dos Reis. Esse ponto concentra o lançamento de esgotos captados oficialmente, que somam-se com o que é lançado in natura na represa, advindo da Vila Cachoeirinha. Ao lado desse ponto encontra-se uma escola de ensino fundamental, nível I, freqüentada por crianças de até 10 anos de idade. Foram realizadas análises da qualidade 
das águas superficiais, utilizando-se os métodos padronizados(*) no ponto de lançamento de esgotos concentrados, citado acima. Abaixo selecionamos os achados mais relevantes para a avaliação da qualidade da água, coletada no período de verão ( estação chuvosa) e período de inverno(estação seca associada a baixas temperaturas) no ponto crítico, em comparação com os parâmetros estabelecidos pela resolução CONAMA 357/05, para cursos de água classe I e II, categoria das águas superficiais de Campos do Jordão de acordo com o Plano de Bacias local:

\section{Tabela 1 - Resultados da análise da qualidade da água superficial no Córrego Brejo Grande}

\begin{tabular}{|c|c|c|c|}
\hline Parâmetros de Análise & $\begin{array}{ll}\text { Córrego } & \text { Brejo } \\
\text { Grande } & \\
\text { 24/01/2007* } & \end{array}$ & $\begin{array}{l}\text { Córrego Brejo } \\
\text { Grande } \\
\text { 25/06/2007* }\end{array}$ & $\begin{array}{l}\text { Conama } \\
\text { Parâmetros } \text { padrão } \\
\text { para a Classe II }\end{array}$ \\
\hline Cor aparente & 250 & 400 & $75 \mathrm{mg} \mathrm{Pt} / \mathrm{L}$ \\
\hline Turbidez & 177 & 127 & 100 UNT \\
\hline Bactérias Heterotróficas & 87.000 & 1.372 .800 & \\
\hline Óleos e graxas & $0 \mathrm{mg} / \mathrm{L}$ & $45,2 \mathrm{mg} / \mathrm{L}$ & Virtualmente ausentes \\
\hline Surfactantes & $0,17 \mathrm{mg} / \mathrm{L}$ & $7,72 \mathrm{mg} / \mathrm{L}$ & Virtualmente ausentes \\
\hline $\mathrm{DBO}$ & 14 & 173 & Até $5 \mathrm{mg} / \mathrm{L}$ \\
\hline $\mathrm{OD}$ & 4,4 & 2,8 & Não inferior a $5 \mathrm{mg} / \mathrm{L}$ \\
\hline Fósforo total & 0,39 & 3,69 & $0,05 \mathrm{mg} / \mathrm{L}$ \\
\hline Mercúrio & 0,0007 & $<0,0002$ & $0,0002 \mathrm{mg} / \mathrm{L}$ \\
\hline Ferro & 2,5 & 1,63 & $0,3 \mathrm{mg} / \mathrm{L}$ \\
\hline $\begin{array}{l}\text { Coliformes } \\
\text { Termotolerantes }\end{array}$ & 410.600 & 24.196 .000 & $\begin{array}{l}\text { Qualidade satisfatória } \\
\text { até } 1.000 / 100 \mathrm{ml}\end{array}$ \\
\hline E. coli & 61.310 & 17.329 .000 & $\begin{array}{l}\text { Qualidade satisfatória } \\
\text { até } 800 / 100 \mathrm{ml}\end{array}$ \\
\hline
\end{tabular}

* amostra coletada sem período de chuva registrado 24 horas antes.

Como pode ser observada, a qualidade desse corpo hídrico, está incrivelmente degradada, e em completo desacordo com a legislação vigente, expondo a população à graves riscos de saúde, especialmente se considerarmos que a área de coleta está ao lado de uma das escolas pública de Ensino Fundamental, parceiras do projeto e cujos estudantes se encontram em uma faixa etária de 5 a 10 anos de idade. Nesse caso a problemática foi ainda maior pelo fato da represa, à montante, ter sido desassoreada sem qualquer cuidado, aumentando em muito o grau de periculosidade da área em torno do corpo de água. Uma clara demonstração desse fato, foi a considerável elevação da taxa de Escherichias coli da ordem de 60.000 (sessenta mil) para mais de 17.000.000 (dezessete milhões) após as ações de desassoreamento na represa Itatinga. Lembramos que essas bactérias são patogênicas e basta um único indivíduo para causar doenças graves tais como conjuntivites, diarréias, pielonefrites entre outras infecções, especialmente em crianças, como as que freqüentam a escola ao lado do ponto de coleta. Um outro dado relevante foi a quantidade de Oxigênio dissolvido que baixou ainda mais, após as ações na represa, novamente favorecendo a proliferação e a manutenção de outros agentes patogênicos, tais como bactérias anaeróbias facultativas. Atualmente a represa encontra-se em estado de recuperação para o lazer da população que tinha e tem livre acesso ao local, portanto recomenda-se que novos testes sejam realizados com a finalidade de se 
determinar a atual condição da represa e quais os impactos sobre o corpo de água, bem como sobre a bacia como um todo.

\subsection{Estimativa do volume de esgoto doméstico lançado na área}

Em Campos do Jordão, a cobertura de coleta de esgoto é de cerca de $40 \%$, segundo dados da SABESP e não há tratamento de esgoto. $\mathrm{Na}$ área de estudo, a coleta também apresenta baixo índice de cobertura, de acordo com o mapa síntese. Ainda os despejos "in natura" estão concentrados em um único ponto, haja vista as condições encontradas nas água da lagoa Itatinga. De acordo com os dados obtidos, o volume de lançamentos "in natura" na área considerada crítica por este estudo é de $\mathbf{6 4 0 . 0 0 0 ~ L / d i a , ~ g e r a n d o ~ u m a ~ d e m a n d a ~ b i o q u i ́ m i c a ~ d e ~}$ oxigênio $173 \mathrm{mg} / \mathrm{L}$. Essa carga é despejada diretamente na represa, determinando uma situação de calamidade pública, expondo não só os moradores da área às doenças de veiculação hídrica, mas os moradores e visitantes da cidade como um todo, já que a represa é um importante contribuinte do Rio Capivari que atravessa a área urbana de Campos do Jordão.

\section{Conclusões do estudo sobre os problemas da otimização da rede de coleta e tratamento de esgoto}

Para a avaliação da rede de distribuição e coleta foi utilizado além da visita a campo, um mapa com a rede de água existente e a rede de água/esgoto existentes, na escala 1:3.000 fornecido pela SABESP, com dados de 2004 e que segundo consulta realizada a SABESP em fevereiro de 2009, encontra-se atualizado, com exceção de poucas áreas novas, que não fazem parte da área de abrangência do atual projeto. Diante dos dados obtidos, a rede de coleta e afastamento deverá ser ampliada de forma a impedir o lançamento de cerca de $640.000 \mathrm{~L} /$ dia de carga de esgoto bruto que atualmente é lançada na área. Um dos aspectos importantes a ser considerado, é o histórico de instabilidade geológica determinado através de levantamento realizado pelo Instituto de Pesquisas Tecnológicas (IPT) no ano de 2000. Ocorre que porções da área de estudo apresentam alto risco de escorregamento com enclaves de habitações que deveriam ter sido desocupadas desde os dramáticos eventos ocorridos na região no ano de 2000. A própria inclinação do terreno bem acima dos $30^{\circ}$ demonstra a condição crítica da área. Como contraponto, agregue-se a isso, a situação dos moradores que ganharam na justiça o direito de regularização fundiária, já que a área é habitada a mais de 20 anos, pelos mesmos proprietários, salvo alguns poucos habitantes das habitações mais precárias na entrada da área. Isto posto, fica claro que o presente estudo demonstra que caso as áreas de ocupação consolidada caso não recebam soluções especiais para otimização da coleta, poderão comprometer a futura operação da Estação de Tratamento de Esgoto a ser implantada em nossa cidade pela Sabesp. Acompanhando uma tendência mundial, desenvolvem-se constantemente modelos de sistemas de tratamento de esgotos mais eficientes , adaptáveis às áreas, com espaços cada vez mais limitados. Portanto, admitindo que não foi previsto, um emissário para o afastamento em direção dos coletores tronco, que transportarão os resíduos urbanos à futura Estação de Tratamento de Esgotos, ou que, dadas as condições da área não poderá ser implantada rede de coleta de forma usual, um modelo de estação compacta poderá ser utilizado, eliminando-se a imensa carga poluidora que a área pesquisada lança diariamente no Rio Capivari. Apesar da área encontrar-se em litígio, pode ser considerada de interesse social, assim através da associação de moradores do bairro, poderiam ser organizados mutirões para a construção de um sistema de coleta de esgoto. Através da própria associação em parceria com o serviço social da prefeitura, as habitações mais precárias poderiam ser removidas, diminuindo a situação de risco. Um outro aspecto importante a ser considerado é a questão da drenagem urbana que deveria ser projetada, visando minimizar o efeito de escoamento sobre as tubulações de esgoto a serem instaladas. Essas ações criariam uma situação de gerenciamento do risco da área, melhorando as 
condições sócio-ambientais. Um outro ponto importante a ser considerado, é a questão da ocupação das margens dos cursos de água e a falta de regularização fundiária, o que determina a construção e manutenção de habitações precárias, determinando uma situação de impasse com o Poder Judiciário, Administração Pública, Órgãos fiscalizadores e Comunidade. Nossas pesquisas indicaram que $70 \%$ dos moradores da área afirmam que possuem casa própria, mesmo habitando áreas invadidas, isto indica que a comunidade possui uma forte relação com a área e portanto poderia atuar de forma positiva para a melhoria das condições ambientais extremamente críticas da área.

Um dos princípios fundamentais da Política Nacional de Recursos Hídricos é o conceito de Bacia Hidrográfica, isto é, o corpo de água não pode ser pensado apenas em termos de limites políticos, assim a degradação que acontece a um elemento desse corpo hídrico, pode comprometer todo o sistema hídrico da Unidade de Gerenciamento de Recursos Hídricos. A carga poluidora lançada pela área de estudo, do presente projeto, está comprometendo seriamente toda a água superficial e possivelmente a subterrânea, considerando que nossa região não dispõe de dados atualizados, nem sobre a vazão, nem sobre a extensão do aqüífero. Somem-se a essa constatação, os fatos de que a demanda consuntiva encontra-se próxima do limite de fornecimento dos mananciais e de que existe um consumo irregular (sem concessão de outorgas) de volume desconhecido da água subterrânea.

Campos do Jordão vem discutindo a implantação de um sistema eficiente de coleta e tratamento de esgotos nos últimos 15 anos. Apesar do empenho de diferentes atores sociais, ainda temos baixa cobertura de coleta, lançamentos irregulares de esgotos junto ao sistema pluvial, invasão de áreas verdes acompanhadas de destruição das matas ciliares, com ocupação das várzeas por todos os tipos de construções. O presente projeto permitiu identificar áreas que poderão não ser atendidas, quando da implantação do sistema de tratamento de esgoto, previsto para 2012. O projeto permitiu a discussão de algumas possibilidades para áreas com características complexas. De acordo com a atual situação de ocupação do solo urbano, vários bairros possuem áreas iguais ou maiores a do presente estudo, que caso não sejam contempladas com um manejo diferenciado, continuarão a lançar uma imensa carga poluidora na bacia. Assim, ironicamente, mesmo que futura estação de tratamento de esgoto utilizasse a mais moderna tecnologia disponível, teria sua eficiência seriamente comprometida, devido a presença de extensas áreas urbanas, com alto adensamento populacional e portanto, alto potencial de poluição, com características tais que não poderiam ser incorporadas pelo sistema padrão de coleta de tratamento de esgoto.

\section{Referências}

\section{Manual}

Secretaria do Meio Ambiente. Coordenadoria de Planejamento Ambiental Estratégico e Educação Ambiental. Manual para Elaboração, Administração e Avaliação de Projetos Socioambientais.-São Paulo:SMA/CPLEA,2005.

Relatório técnico:

Junior,J.L.R.;Ogura,A.T.;Macedo. E.S.;Nóris,C.D.;Alberto, M.C.;Santos,P.H.P. Acidentes associados a movimentos gravitacionais de massa ocorridos no município de Campos de Jordão,SP,em janeiro de 2000:Ações técnicas após o desastre. Publicação IPT 2815, São Paulo, 2002. 